Research article

\title{
The DNMT3B C $\rightarrow$ T promoter polymorphism and risk of breast cancer in a British population: a case-control study
}

\author{
Karen G Montgomery ${ }^{1}$, Mira CP Liu 1 , Diana M Eccles ${ }^{2}$ and lan G Campbell ${ }^{1}$
}

\author{
1Victorian Breast Cancer Research Consortium, Cancer Genetics Laboratory, Peter MacCallum Cancer Center, East Melbourne, Victoria, Australia \\ ${ }^{2}$ Wessex Clinical Genetics Service, Princess Anne Hospital, Southampton, UK \\ Corresponding author: lan G Campbell, ian.campbell@petermac.org
}

Received: 5 Feb 2004 Revisions requested: 4 Mar 2004 Revisions received: 23 Apr 2004 Accepted: 30 Apr 2004 Published: 19 May 2004

Breast Cancer Res 2004, 6:R390-R394 (DOI 10.1186/bcr807)

(C) 2004 Montgomery et al.; licensee BioMed Central Ltd. This is an Open Access article: verbatim copying and redistribution of this article are permitted in all media for any purpose, provided this notice is preserved along with the article's original URL.

\begin{abstract}
Background Gene promoter methylation is an important regulator of expression and is a key epigenetic factor in tumorigenesis. DNA methylation is mediated by DNA methyltransferases (DNMTs), of which three active forms have been identified: DNMT1, DNM3A and DNMT3B. The $\mathrm{C} \rightarrow T$ transition polymorphism (C46359T) in the promoter of the $D N M T 3 B$ gene, which significantly increases transcriptional activity, has been postulated to increase the propensity for promoter-hypermethylation-mediated silencing of tumour suppressor genes.
\end{abstract}

Methods To determine the role of this polymorphism in breast cancer, we genotyped 352 cases and 258 controls from a British population. The breast cancer cases were selected on the basis of either an age at onset of less than 40 years, a family history of breast cancer irrespective of age at onset, or bilateral breast cancer diagnosed after 39 years of age irrespective of family history.

Results The $\mathrm{C}$ allele was found to be more common in case subjects than in control subjects (cases, 0.59; controls, 0.54) corresponding to a nominally significant increase in breast cancer risk to heterozygotes and $\mathrm{CC}$ homozygotes (odds ratio $1.51,95 \%$ confidence interval $1.01-2.25$ ) in the dominant inheritance model.

Conclusions Our findings contrast with those of a previous study, which showed that individuals carrying at least one $T$ allele have a significantly increased risk of developing lung cancer. This discrepancy might be an artefact resulting from a chance variation, or it might point to differing influences of promoter hypermethylation in these cancer types.

Keywords: breast cancer, DNMT3B, methylation, polymorphism

\section{Introduction}

Genetic factors are increasingly being recognised as a major contributor to cancer risk [1,2]. Although genes with highly penetrant mutations, exemplified by BRCA1 and $B R C A 2$, confer a high relative risk, they are rare in the general population and therefore the population attributable risk is low. It is now suspected that most of the population attributable genetic risk is due to relatively common 'lowpenetrance' disease-associated allelic variants. Although these variants might confer a small absolute cancer risk, this is outweighed by the fact that they are very common in the general population [2]. Recognition of this fact has led to an explosion of epidemiological studies searching for common polymorphisms in genes that might represent susceptibility alleles $[3,4]$. Among the most promising candidates are genes involved in the maintenance of genomic integrity and DNA repair, which include genes such as
BRCA1, BRCA2 and TP53 [5-8]. These and other functionally related genes are currently under intense scrutiny for common low-penetrance cancer-predisposing alleles. However, another group of genes, which have not received much attention, are those responsible for epigenetic modification of DNA through CpG methylation.

DNA methylation is a major epigenetic modification involving the addition of a methyl group to the $5^{\prime}$ position of a cytosine in a $\mathrm{CpG}$ dinucleotide. These dinucleotides are not equally distributed throughout the genome: most are clustered in so-called 'CpG islands', which span the promoter region and the first few exons of most housekeeping and tumour suppressor genes [9]. Most CpG dinucleotides present in islands are unmethylated in normal tissues, whereas those present in other regions of the genome are usually methylated. However, during the process of 
carcinogenesis this balance is reversed. Consequently, even though many gene promoters become hypermethylated, overall cancers are hypomethylated compared with matching normal tissues. Hypermethylation of $\mathrm{CpG}$ islands located in the promoter regions of tumour suppressor genes is now firmly established as an important, if not the most important, mechanism of tumour suppressor gene inactivation [10] and might also influence genomic stability.

DNA methylation is mediated by a family of DNA methyltransferases (DNMTs), of which three active forms (DNMT1, DNMT3A and DNMT3B) have been identified in mammalian cells [11]. An overall increase in the enzymatic DNA methyltransferase activity of the two maintenance DNA methyltransferases, DNMT1 and DNMT3B, has been shown to occur in tumours [12-17].

The DNMT3B gene, located on chromosome 20q11.2, contains a $\mathrm{C} \rightarrow \mathrm{T}$ transition polymorphism (C46359T) at a novel promoter region, -149 base pairs from the transcription start site, which in assays in vitro confers a $30 \%$ increase in promoter activity $[11,18]$. The first evidence that this polymorphism might be associated with cancer was reported in lung cancer in which carriers of the T allele, particularly heterozygotes, had a significant increase in risk (odds ratio [OR] 2.13, 95\% confidence interval [Cl] 1.473.08) [11]. Although the mechanism for this association was not clear, it was postulated that the $T$ variant might upregulate DNMT3B expression and thereby increase the propensity for the epigenetic silencing of some tumour suppressor genes. Such an association is supported by the observation that DNMT3b is upregulated in lung cancer cell lines [19], and comparative genomic hybridization studies have shown that the $20 \mathrm{q}$ region is often amplified in primary lung cancers [20].

In the present study we evaluated the association between the DNMT3B C46359T polymorphism and breast cancer risk in a hospital-based case-control study in a British population.

\section{Materials and methods Subjects}

Subjects were recruited in a hospital-based case-control study of genes predisposing to breast cancer, performed at breast clinics in the South of England. The breast cancer cases were selected on the basis of either an age at onset of less than 40 years (203 cases), a family history of breast cancer (defined as two or more cases of breast cancer in a first-degree or second-degree female relative) irrespective of age at onset (105 cases), or bilateral breast cancer diagnosed after 39 years of age irrespective of family history (44 cases). All breast cancer cases were systematically ascertained through breast clinics in the South of England as described previously $[21,22]$. In brief, women were invited to take part in a research study, the primary goal of which was to ascertain and verify family histories for segregation analysis. The breast cancer cases diagnosed before 40 years of age were consecutively ascertained without regard to family history. The group of women with bilateral breast cancer were ascertained in the same clinics but the selection criterion was the presence of bilateral breast cancer diagnosed after 39 years of age. The familial breast cancer cases consisted of women presenting to the same clinics with a strong family history of breast or ovarian cancer or both. Family histories were verified as far as possible from medical records and death certificates. Blood was taken from all recruits who consented to molecular analysis for breast cancer predisposition genes. The age range of case participants was 19-76 years, with a mean of 40 .

The control subjects $(n=258)$ were all white female volunteers who were either staff at the Princess Anne Hospital, Southampton $(n=117)$ or outpatients $(n=141)$ attending for obstetric-related, non-neoplastic disease conditions. The age of the controls ranged from 18-84 years, with a mean of 39 .

For all groups, normal genomic DNA was prepared from blood lymphocytes. Epidemiological data such as reproductive factors, oral contraceptive use, smoking and obesity were not available for either the cases or controls. However, both control and cancer groups were residents of the greater Southampton area, which is a predominantly Anglo-Saxon population.

\section{Molecular analysis}

A total of 352 case and 258 control subjects were genotyped for the DNMT3B C46359T polymorphism by using a dual-colour allele-specific polymerase chain reaction (PCR) assay. PCR amplifications were performed with a common forward primer (5'-TGCTGTGACAGGCAGAGCAG-3') and HEX and FAM labelled reverse primers (5'GCCTTAGGTGACTGGAGGCCTG-3' and 5'-GGCTTAGGTGACTGGAGGCCTA-3', respectively). All PCRs were performed in $10 \mu$ volumes containing $10-200 \mathrm{ng}$ of genomic DNA, 200 nM dNTPs (Promega, Annandale, NSW, Australia), $25 \mathrm{ng}$ of each primer, $1 \times$ ReddyMix buffer (Abgene, Epsom, Surrey, UK) and 0.2 units of Thermoprime Plus DNA Polymerase (Abgene). PCR amplification cycle conditions involved an initial denaturation step at $94^{\circ} \mathrm{C}$ for $5 \mathrm{~min}, 40$ cycles of denaturation at $94^{\circ} \mathrm{C}$ for $20 \mathrm{~s}$, annealing at $68^{\circ} \mathrm{C}$ for $20 \mathrm{~s}$, and extension at $72^{\circ} \mathrm{C}$ for $45 \mathrm{~s}$. This was followed by a further extension step at $72^{\circ} \mathrm{C}$ for 5 $\mathrm{min}$. The alleles were then separated through an unstained $3 \%$ agarose gel and analysed with a scanning laser fluorescence imager (Molecular Imager FX; Bio-Rad); 10\% of the genotyping was confirmed with a PCR and restriction fragment length polymorphism assay described previously [3]. 


\section{Statistical methods}

The Hardy-Weinberg equilibrium assumption was assessed by the standard methods.

The data were considered by using models assuming either dominant inheritance (that is, women with one or two $\mathrm{C}$ alleles had the same relative hazard), co-dominant inheritance (that is, the relative hazard differed between women with one $\mathrm{C}$ allele and those with two $\mathrm{C}$ alleles) or recessive inheritance (that is, only women with two $\mathrm{C}$ alleles were at increased risk).

Case subjects were also stratified by family history, bilateral breast cancer status and age of breast cancer onset. For all analyses, the control subjects were treated as a single group without stratification.

Comparisons of frequencies were analysed with Fisher's exact test. ORs and $95 \% \mathrm{Cls}$ were calculated by using the relevant $2 \times 2$ contingency tables. All statistical calculations were two-sided and performed with InStat version 3.01 (GraphPad Software Inc., San Diego, CA). $P<0.05$ was considered statistically significant. Power calculations were performed with the online Binomial Distribution-Case Control Power Calculator available from the UCLA Department of Statistics http://calculators.stat.ucla.edu/.

\section{Results}

There was no evidence of a deviation from Hardy-Weinberg equilibrium among the case or control subjects. The frequency of the $\mathrm{C}$ allele in control subjects (0.54) was similar to that found in the previous study among Caucasians (0.56); however, the frequency in case subjects was substantially lower (0.59 versus 0.51$)$ [3]. All the breast cancer cases have been screened for germline BRCA1 and BRCA2 mutations [22]. A total of $18 B R C A 1$ and 9 $B R C A 2$ mutations were detected and the frequencies of the DNMT3b genotypes were $25.9 \%$ TT, $44.5 \%$ TC and $29.6 \%$ CC, which was not significantly different from the breast cancer group as a whole $(P=0.22)$.

Table 1 shows the breast cancer risk (given by OR, 95\% Cl and $P$ value) for the different DNMT3B C46359T polymorphism genotypes according to co-dominant and dominant models of inheritance. Under a dominant model of inheritance, there was a nominally significant increase in breast cancer risk (OR 1.51, 95\% Cl 1.01-2.25) when grouping CC and CT genotypes and comparing them with the TT genotype. A similar excess of $\mathrm{C}$ allele genotypes was also observed in cases under co-dominant and recessive models, but these did not reach statistical significance. The frequency of the $\mathrm{C}$ allele was higher among the breast cancers than the controls ( 0.59 versus 0.54$)$ but this difference was not statistically significant $(P=0.13)$.

The distribution of genotypes among subjects diagnosed with breast cancer at the age of less than 40 years and among subjects with a family history of breast cancer (defined as an individual with two or more cases of breast cancer in a first-degree or second-degree female relative) and/or with bilateral breast cancer, was similar to that observed for the entire cohort. Under each model of inheritance, a higher frequency of genotypes containing a $\mathrm{C}$ allele was observed than in the controls, although these differences were not statistically significant. Analysis of the data according to the criteria on which the cases were recruited revealed that the main contribution to the significant result came from the under-40 and family history groups (data not shown). The cases selected on the basis of bilateral breast cancer showed a genotype distribution very similar to the control group (TT, 25.0\%; CT, 43.2\%; $\mathrm{CC}, 31.8 \%$ ). The study had $80 \%$ power to detect an OR of 1.6 or more for carriers heterozygous for the $\mathrm{C}$ allele and an OR of 1.7 or more for carriers homozygous for the $\mathrm{C}$ allele.

Table 1

DNMT3B genotype frequencies of breast cancer cases and controls

\begin{tabular}{|c|c|c|c|c|c|c|c|c|c|c|c|}
\hline Group & $\begin{array}{l}\text { No. of } \\
\text { subjects }\end{array}$ & $\begin{array}{l}\text { TT No. } \\
(\%)\end{array}$ & $\begin{array}{c}\text { TC No. } \\
(\%)\end{array}$ & $\mathrm{Pa}$ & OR $(95 \% \mathrm{Cl})$ & $\begin{array}{c}\text { CC No. } \\
(\%)\end{array}$ & $\mathrm{Pa}$ & $\begin{array}{l}\text { OR } \\
(95 \% \mathrm{Cl})\end{array}$ & $\begin{array}{l}\mathrm{TC}+\mathrm{CC} \\
\text { No. }(\%)\end{array}$ & $P a$ & $(\mathrm{OR}, 95 \% \mathrm{Cl})$ \\
\hline Control & 258 & $60(23.3)$ & $116(45.0)$ & & & 82 (31.8) & & & $198(76.8)$ & & \\
\hline All breast cancer & 352 & $59(16.8)$ & $173(49.1)$ & 0.06 & $\begin{array}{l}1.52 \\
(0.99-2.33)\end{array}$ & $120(34.1)$ & 0.10 & $\begin{array}{l}1.49 \\
(0.94-2.35)\end{array}$ & $293(83.2)$ & 0.05 & $\begin{array}{l}1.51 \\
(1.01-2.25)\end{array}$ \\
\hline Under $40^{b}$ & 212 & $34(16.0)$ & $103(48.6)$ & 0.08 & $\begin{array}{l}1.57 \\
(0.95-2.58)\end{array}$ & $75(35.4)$ & 0.09 & $\begin{array}{l}1.61 \\
(0.96-2.73)\end{array}$ & $178(84.0)$ & 0.06 & $\begin{array}{l}1.21 \\
(1.01-1.45)\end{array}$ \\
\hline $\begin{array}{l}\text { Family history } \\
\text { bilateral } \\
\text { cancerc }^{\mathrm{c}}\end{array}$ & 245 & $46(18.5)$ & $119(47.8)$ & 0.24 & $\begin{array}{l}1.34 \\
(0.84-2.12)\end{array}$ & 84 (33.7) & 0.26 & $\begin{array}{l}1.34 \\
(0.82-2.18)\end{array}$ & $203(81.5)$ & 0.19 & $\begin{array}{l}1.34 \\
(0.87-2.06)\end{array}$ \\
\hline
\end{tabular}

OR, odds ratio; $\mathrm{Cl}, 95 \%$ confidence interval. a $P$ was determined by Fisher's exact test (two-sided) for the relevant genotype, with the TT homozygotes as reference. bThis group includes cases that were originally selected on the basis of family history but where the diagnosis was made earlier than 40 years of age. cThis group includes cases that were originally selected on the basis of diagnosis earlier than 40 years of age but where there was also bilateral disease or a family history of cancer. 


\section{Discussion}

DNMT3B has been postulated to be important in cancer because of its ability to mediate de novo DNA methylation, which in turn might silence tumour suppressor gene expression through promoter hypermethylation. Overexpression of DNMT3B has been observed in some cancer types [13-17], providing circumstantial evidence for a role in cancer development. In this context, the C46359T promoter polymorphism, which is reported to increase promoter activity, represents a highly plausible cancerpredisposing allele [11].

Our study of British women diagnosed with early-onset breast cancer, bilateral breast cancer and/or with a family history of breast cancer has suggested that individuals carrying one or more $\mathrm{C}$ alleles for the DNMT3B C46359T promoter polymorphism have a nominally significant increase in breast cancer risk in comparison with TT homozygotes. If we assume that the T allele is associated with increased promoter activity, our findings are counter to the underlying hypothesis that higher DNMT3B activity would increase de novo methylation of tumour suppressor gene promoters, and would thereby confer increased cancer risk. Because the association with the $\mathrm{C}$ allele was of marginal significance $(P=0.05)$, and because we could not adjust for known breast cancer risk factors, we cannot exclude the possibility that such confounding factors might have led to a type I error. However, confounding due to differences in ethnicity is unlikely because both the cases and the controls were residents of Southampton or nearby towns, which is a predominantly Anglo-Saxon population.

This is the first study of any DNMT3b polymorphism in breast cancer. The only other cancer association study reported an increased risk of lung cancer in carriers of the allele with putatively higher activity (the $T$ allele) [11]. Intriguingly, the lung cancer study found the most pronounced effect with the CT heterozygotes under a co-dominant model, which is similar to our observation. This raises the possibility that intermediate DNMT3B activity might be more biologically conducive to cancer development than either extreme in activity. Alternatively, it is possible that both associations are real and that the discrepancy is a reflection of differing roles of DNMT3B in different cell types. It has certainly been noted that different splice variants of DNMT3B, with potentially altered catalytic activity, are expressed in a tissue-specific manner [17]. In addition, it has been shown that repression of DNMT3B activity does not result in the re-expression of all hypermethylated tumour suppressor genes in some cell systems [23], suggesting that there is a complex interplay of the different DNMTs that might operate in a tissue-specific manner. Finally, it is possible that linkage disequilibrium of the C46359T promoter polymorphism alleles to other, as yet unidentified, functional polymorphisms could explain the lack of consensus with regard to disease association. This possibility seems very likely given the very recent finding that a T/C polymorphism (T46222C) located 138 base pairs upstream of the C46359T polymorphism decreases promoter activity by up to $90 \%$ [18]. In addition, an inverse allele-dose response between DNMT3b mRNA expression and the number of $\mathrm{T}$ alleles of the C46359T polymorphism has been reported in bladder cancer, suggesting that it might be the $\mathrm{C}$ allele that is associated with higher DNMT3b expression [24]. Clearly, our understanding of the genetic factors influencing the expression of DNMT3b is incomplete, and definitive evidence defining how each allelic variant influences expression is required. Nevertheless, the existing data suggest that genetic variants located in the DNMT3b promoter can profoundly influence mRNA expression.

\section{Conclusions}

Our study suggests that there may be an association between the $\mathrm{C}$ allele of the DNMT3B promoter polymorphism and women with early-onset breast cancer, bilateral breast cancer or with a family history of the disease. As this is the first report of this polymorphism in breast cancer, independent studies are needed to verify this association.

\section{Competing interests}

None declared.

\section{References}

1. Weber BL, Nathanson KL: Low penetrance genes associated with increased risk for breast cancer. Eur J Cancer 2000 36:1193-1199.

2. Ponder BA: Cancer genetics. Nature 2001, 411:336-341.

3. Dunning AM, Healey CS, Pharoah PDP, Teare MD, Ponder BAJ, Easton DF: A systematic review of genetic polymorphisms and breast cancer risk. Cancer Epidemiol Biomarkers Prev 1999, 8:843-854.

4. Coughlin SS, Piper M: Genetic polymorphisms and risk of breast cancer. Cancer Epidemiol Biomarkers Prev 1999, 10:1023-1032

5. Wenham RM, Schildkraut JM, McLean K, Calingaert B, Bentley RC, Marks J, Berchuck A: Polymorphisms in BRCA1 and BRCA2 and risk of epithelial ovarian cancer. Clin Cancer Res 2003 , 9:4396-4403.

6. Keshava C, Frye BL, Wolff MS, McCanlies EC, Weston A: Waf-1 (p21) and p53 polymorphisms in breast cancer. Cancer Epidemiol Biomarkers Prev 2002, 11:127-130.

7. Wang-Gohrke S, Becher H, Kreienberg R, Runnebaum IB, ChangClaude J: Intron 316 bp duplication polymorphism of p53 is associated with an increased risk for breast cancer by the age of 50 years. Pharmacogenetics 2002, 12:269-272.

8. Healey CS, Dunning AM, Teare MD, Chase D, Parker L, Burn J, Chang-Claude J, Mannermaa A, Kataja V, Huntsman DG, Pharoah PD, Luben RN, Easton DF, Ponder BA: A common variant in BRCA2 is associated with both breast cancer risk and prenatal viability. Nat Genet 2000, 26:362-364.

9. Esteller $\mathrm{M}: \mathbf{C p G}$ island hypermethylation and tumor suppressor genes: a booming present, a brighter future. Oncogene 2002, 21:5427-5440.

10. Jones PA, Baylin SB: The fundamental role of epigenetic events in cancer. Nat Rev Genet 2002, 3:415-428.

11. Shen H, Wang L, Spitz MR, Hong WK, Mao L, Wei Q: A novel polymorphism in human cytosine DNA-methyltransferase-3B promoter is associated with an increased risk of lung cancer. Cancer Res 2002, 62:4992-4995. 
12. Clark SJ, Melki J: DNA methylation and gene silencing in cancer: which is the guilty party? Oncogene 2002, 21:5380-5387.

13. Yakushiji T, Uzawa $K$, Shibahara $T$, Noma $H$, Tanzawa $H$ : Overexpression of DNA methyltransferases and CDKN2A gene methylation status in squamous cell carcinoma of the oral cavity. Int J Oncol 2003, 22:1201-1207.

14. Saito $Y$, Kanai $Y$, Nakagawa $T$, Sakamoto $M$, Saito $H$, Ishii $H$, Hirohashi S: Increased protein expression of DNA methyltransferase (DNMT) 1 is significantly correlated with the malignant potential and poor prognosis of human hepatocellular carcinomas. Int J Cancer 2003, 105:527-532.

15. Patra SK, Patra A, Zhao H, Dahiya R: DNA methyltransferase and demethylase in human prostate cancer. Mol Carcinog 2002, 33:163-171.

16. Mizuno $S$, Chijiwa $T$, Okamura $T$, Akashi $K$, Fukumaki $Y$, Niho $Y$, Sasaki $\mathrm{H}$ : Expression of DNA methyltransferases DNMT1, 3A, and $3 B$ in normal hematopoiesis and in acute and chronic myelogenous leukemia. Blood 2001, 97:1172-1179.

17. Robertson KD, Uzvolgyi E, Liang G, Talmadge C, Sumegi J, Gonzales FA, Jones PA: The human DNA methyltransferases (DNMTs) 1, 3a and 3b: coordinate mRNA expression in normal tissues and overexpression in tumors. Nucleic Acids Res 1999, 27:2291-2298.

18. Wang $L$, Liu Z, Mao L, Spitz MR, Wei Q: Functional relevance of C46359T in the promoter region of human DNMT3B6 [Abstract]. Proc AACR 2004, 45:2913.

19. Sato $M$, Horio $Y$, Sekido $Y$, Minna JD, Shimokata $K$, Hasegawa $Y$ : The expression of DNA methyltransferases and methyl-CpGbinding proteins is not associated with the methylation status of p14(ARF), p16(INK4a) and RASSF1A in human lung cancer cell lines. Oncogene 2002, 21:4822-4829.

20. Luk C, Tsao MS, Bayani J, Shepherd F, Squire JA: Molecular cytogenetic analysis of non-small cell lung carcinoma by spectral karyotyping and comparative genomic hybridization. Cancer Genet Cytogenet 2001, 125:87-99.

21. Eccles D, Marlow A, Royle G, Collins A, Morton NE: Genetic epidemiology of early onset breast cancer. J Med Genet 1994, 31:944-949.

22. Eccles DM, Englefield P, Soulby MA, Campbell IG: BRCA1 mutations in southern England. Br J Cancer 1998, 77:2199-2203.

23. Soejima K, Fang W, Rollins BJ: DNA methyltransferase $3 b$ contributes to oncogenic transformation induced by SV40T antigen and activated Ras. Oncogene 2003, 22:4723-4733.

24. Hazra A, Gu J, Zhu Y, Grossman HB, Spitz MR, Wu X: DNMT3b and bladder cancer risk: from genotype to phenotype [Abstract]. Proc AACR 2004, 45:1604. 